\title{
Improving gluten-free buckwheat bread by sourdough fermentation and addition of arabinoxylan and pyranose 2-oxidase
}

\section{Verbesserung von glutenfreiem Buchweizenbrot durch Sauerteigfermentation und Zugabe von Arabinoxylan und Pyranose 2-oxidase}

\author{
Elena Zand ${ }^{1}$, Denisse Bender ${ }^{1}$, Stefano D’Amico ${ }^{1}$, Sandor Tömösközi ${ }^{2}$, Henry Jaeger ${ }^{1}$, Regine Schoenlechner ${ }^{1}$ \\ ${ }^{1}$ Department of Food Science and Technology, University of Natural Resources and Life Sciences Vienna (BOKU), Muthgasse 18, 1190, \\ Vienna, Austria \\ ${ }^{2}$ Department of Applied Biotechnology and Food Science, Budapest University of Technology and Economics (BME), Müegyetem rkp. 3, 1111, \\ Budapest, Hungary \\ * Correspondence: regine.schoenlechner@boku.ac.at
}

Received: 17 September 2018, received in revised form: 14 November 2018, accepted: 15 November 2018

\begin{abstract}
Summary
The purpose of this research was to improve the functional properties of gluten-free (GF) wholemeal buckwheat bread by sourdough fermentation and addition of arabinoxylan (AX) and pyranose 2-oxidase (POx). AXs are able to cross-link to other AX molecules under acidic conditions, which is supported by the addition of oxidizing enzymes (e.g., POx). On a first approach, the optimal sourdough concentration (\% acidification of total flour weight) was adjusted. The best results were seen at an acidification of $82 \%$ of total flour weight. The optimal dosage of $3 \% \mathrm{AX}$ and $1 \mathrm{nkat} \mathrm{POx} / \mathrm{g}$ flour was able to increase the specific volume from 1.80 to $1.93 \mathrm{~cm}^{3} / \mathrm{g}$ bread and reduce the firmness from 9.61 to $4.69 \mathrm{~N}$ compared to the control bread and presented an acceptable relative elasticity of $62.20 \pm 0.96 \%$. These effects were then compared in breads produced from wholemeal and refined buckwheat flour. Interestingly, the wholemeal buckwheat bread showed a significantly lower firmness and higher relative elasticity than the bread from refined flour, which can be mainly attributed to the higher protein and dietary fibre content of wholemeal flour. Overall, this study suggested that addition of AX and POx could positively increase the quality of GF buckwheat bread.
\end{abstract}

Keywords: Arabinoxylan, pyranose 2-oxidase, buckwheat, gluten-free bread

\section{Zusammenfassung}

Ziel dieser Arbeit war es, die funktionellen Eigenschaften von glutenfreiem (GF) Vollkornbuchweizenbrot durch Sauerteigfermentation und Zugabe von Arabinoxylan (AX) und Pyranose 2-oxidase (POx) zu verbessern. Arabinoxylane besitzen die Fähigkeit, sich unter sauren Bedingungen mit anderen AX-Molekülen zu vernetzen. Diese Eigenschaft kann durch Zugabe von oxidierenden Enzymen (z.B. POx) gefördert werden. Im ersten Ansatz wurden verschiedene Sauerteigkonzentrationen (\% Versäuerung der Gesamtmehlmenge) verwendet, um die Brotrezeptur zu verbessern. Von den getesteten Konzentrationen zeigte eine Versäuerung von 82 \% der Gesamtmehlmenge die besten Ergebnisse. Eine optimierte Konzentration von 3 \% AX und 1 nkat POx/g Mehl konnte im Vergleich zur Kontrolle das spezifische Volumen von 1,80 auf 1,93 cm $3 / \mathrm{g}$ Brot erhöhen und die Krumenfestigkeit von 9,61 auf 4,69 N senken und zeigte eine akzeptable relative Elastizität (62,20 $\pm 0,96 \%)$. Diese Effekte wurden in weiterer Folge in Broten aus Vollkorn- und Auszugsmehl verglichen. Interessanterweise zeigte das optimierte Vollkornbuchweizenbrot eine signifikant niedrigere Krumenfestigkeit und höhere relative Elastizität als das Brot aus Auszugsmehl. Diese Studie deutet darauf hin, dass eine Zugabe von AX und POx die Qualität von GF Buchweizenbrot positiv beeinflussen kann.

Schlagworte: Arabinoxylan, Pyranose 2-oxidase, Buchweizen, glutenfreies Brot 
Abbreviations: AX: arabinoxylan, Fmax: crumb firmness, dm: dry matter, GF: gluten-free, GOx: glucose oxidase, $\mathrm{H}_{2} \mathrm{O}_{2}$ : hydrogen peroxide, nkat: nanokatal (The katal (kat) expresses the catalytic activity of an enzyme. 16.67 nkat $=1 \mathrm{U}$ (= old enzyme unit)), POx: pyranose 2-oxidase, REL: relative elasticity, R.H.: relative humidity, TTA: titratable acidity.

\section{Introduction}

Bread is a staple food in Western countries that provides essential nutrients to the organism. Thus, the availability of similar GF alternatives is essential to people with glutenrelated disorders (Rosell et al., 2015). To increase the consumer acceptance and meet the requirements of the bakery industry, breads should be characterized by a soft crumb and sufficient dough elasticity to allow gas cell expansion and increase the loaf volume (Rosell et al., 2010). Still most GF breads have an unsatisfying nutritional value and poor functional properties such as deficient gas retention, low loaf volume and crumbly texture (Naqash et al., 2017). Therefore, in recent years, alternative ingredients that imitate the viscoelastic properties of gluten and improve the final bread quality have been investigated (Mir et al., 2016). These include the use of pseudocereals such as buckwheat (Moroni et al., 2011), wholemeal instead of refined flour based recipes (Hager et al., 2012), the application of sourdough (Moroni et al., 2009) and the addition of different enzymes (Renzetti and Rosell, 2016) and hydrocolloids (Mir et al., 2016). Arabinoxylans (AXs) occur naturally in the cell wall of cereals such as rye. Besides their functionality in gluten-containing products, they have been used in GF bread making (Buksa, 2016) as hydrocolloid. AXs consists of a backbone of $\beta$-(1,4)-xylopyranosyl units with arabinofuranosyl substitutions on the $\mathrm{C}(\mathrm{O})-2$ and/or $\mathrm{C}(\mathrm{O})-3$ position and some arabinosyl units are covalently attached to ferulic acids via ester linkages (Grootaert et al., 2007). AX can be categorized as water-soluble and water-insoluble AX (Figueroa-Espinoza et al., 2002), whereof only water-soluble fractions have the ability to form a three-dimensional network with other AXs or other polymers (like lignin or proteins) in the presence of water and oxidizing agents or enzymes, such as hydrogen peroxide $\left(\mathrm{H}_{2} \mathrm{O}_{2}\right)$, POx or glucose oxidase (GOx). As waterinsoluble $\mathrm{AX}$ s are already cross-linked, they are not able to form such gels. Furthermore, the cross-linking ability is associated with the higher molecular weight and substitution degree of water-soluble AX compared to water-insoluble AX and the availability of dimer and trimer ferulic acids. The latter determines the extent of AX gelation, which further increases the water holding capacity of the final product, as water is retained within the network (Izydorczyk and Biliaderis, 2007). Because of these properties, AXs are considered as novel ingredients to improve functional bread properties. Ayala-Soto et al. (2017) reported an improved loaf volume and crumb hardness of GF breads with the use of maize fibre AX; while Bender et al. (2018a) found positive effects of AX and POx addition on rheological properties of buckwheat model systems. In addition, the use of sourdough could positively influence the crosslinking ability of AX as the oxidative gelation of AX is favoured by the acidification of the bread dough (Arendt et al., 2007).

In an appropriate amount, sourdough addition alone can improve the stability and shelf life of GF breads, which generally have a short shelf life and thus prevent microbiological spoilage by production of antifungal compounds against common bread spoilage organisms by sourdoughlactic acid bacteria. Also, functional properties (specific volume and texture) as well as flavour and nutritional value can be enhanced (Moroni et al., 2009).

However, research on GF breads added with AXs is still limited. Hence, the overall objective of this study was to improve the functional properties of gluten-free (GF) bread based on wholemeal buckwheat flour by sourdough fermentation and addition of AX and Pox. This was done to provide new fundamental information for bread manufacturing industries and to people in need of GF products. On the first approach, the optimal sourdough concentration of buckwheat flour bread was adjusted. A response surface methodology was applied to optimize the texture and loaf volume of GF bread using different AX and POx concentrations. In addition, crumb porosity and crust colour were analysed. In the last step, the results found in wholemeal buckwheat flour based breads were compared to the functional properties of breads produced from refined buckwheat flour, as refined flour based breads were suggested to show more desirable functional properties than the wholemeal based ones (Hager et al., 2012).

\section{Material and methods}

\subsection{Materials}

Buckwheat grains were purchased from Caj. Strobl Naturmühle $\mathrm{GmbH}$ (Linz, Austria). To obtain refined buckwheat flour, grains were ground with a laboratory mill 
(FQC-109, Metefém, Hungary) and sieved with a laboratory sieve (AS200, Retsch, Germany) to achieve a standard particle size of $250 \mu \mathrm{m}$ (ISO 3310-1:2016). For wholemeal buckwheat flour, the grains were ground in a pin mill (Pallmann Maschinenfabrik, PXL 18, Zweibrücken, Germany) at $12,000 \mathrm{rpm}$. The chemical composition of wholemeal buckwheat flour was $14.27 \pm 0.02 \% \mathrm{dm}$ (= \% dry matter) protein, $2.87 \pm 0.01 \% \mathrm{dm}$ fat, $67.07 \pm 0.09 \% \mathrm{dm}$ starch, $0.42 \pm 0.04 \% \mathrm{dm}$ soluble dietary fibres, $5.42 \pm 0.20 \% \mathrm{dm}$ insoluble dietary fibres and $2.27 \pm 0.03 \% \mathrm{dm}$ ash; while for refined buckwheat flour, it was $2.27 \pm 0.03 \% \mathrm{dm}$ protein, $2.27 \pm 0.03 \% \mathrm{dm}$ fat, $82.54 \pm 4.26 \% \mathrm{dm}$ starch, $0.13 \pm 0.03 \% \mathrm{dm}$ soluble dietary fibres, $1.51 \pm 0.05 \% \mathrm{dm}$ insoluble dietary fibres and $0.99 \pm 0.00 \% \mathrm{dm}$ (the sum of soluble and insoluble dietary fibre is total dietary fibre). These properties were derived from Bender et al. (2018b), except for the starch content, which was calculated by differences. Rye AX was extracted with calcium hydroxide following the procedure of Bender et al. (2017b) and POx was recombinantly expressed from the white rot fungus Phanerochaete chrysosporium and purified, as explained by Spadiut et al. (2010). A commercial GF rice-based sourdough starter culture (Böcker Reinzucht-Sauerteig-Reis) was purchased from Ernst Böcker GmbH \& Co (Minden, Germany). Sugar and salt were bought from Agrana (Vienna, Austria) and Salinen (Ebensee, Austria), respectively, while instant yeast (SAF-INSTANT) was donated by Lesaffre Austria AG (Wiener Neudorf, Austria).

\subsection{Preparation of gluten-free buckwheat breads and experimental procedure}

To adjust the effect of sourdough on the wholemeal buckwheat bread properties, different sourdough concentrations of $18 \%, 36 \%$ and $54 \%$ of total flour weight were tested. Additionally, $82 \%$ of total flour weight was analysed to make the results comparable to the previous research (Bender et al., 2017a).

To study the effect of AX and POx on GF wholemeal buckwheat bread, a random two factor, three level $\left(2^{2}\right)$ response surface face-centred central composite design was used, which consisted of nine different baking formulations and eleven runs, including three repetitions of the central point, as presented in Table 1. Variable limits (AX: 0-6\%; POx: 0-2 nkat/g flour) were established according to the preliminary tests with the aim to optimize the functional properties. The response variables, namely crumb firmness, relative elasticity and specific volume, as well as pore diameter and gas cell area of the bread crumb were analysed.

Within a third trial, the best bread formulation was additionally tested using refined buckwheat flour and compared to its wholemeal counterpart.

For the preparation of the sourdough, the commercial GF starter culture was dissolved in water at $30{ }^{\circ} \mathrm{C}$ and then manually mixed with flour until complete homogenization took place. The ratio of water, flour and starter culture was 1:1:10. The resulting batter was fermented in a fermenter $(60 / \mathrm{rW}$, MANZ Backtechnik GmbH, Creglingen, Germany) at $30^{\circ} \mathrm{C}$ and $85 \%$ R.H. for 20 h. A simplified recipe, as described by Bender et al. (2018b), was used for wholemeal and refined buckwheat bread, based only on buckwheat flour (100\%), water $(100 \%)$, salt $(1.9 \%)$, sugar (1.9\%), instant yeast $(1.9 \%)$ and sourdough $(82 \%)$ without any further additives (\% of total flour weight, including flour of sourdough and bread preparation). AX was added to the dry ingredients, while $\mathrm{POx}$ was always added to the water. When AX was used, additional water was added to the formulation, according to its water holding capacity ( $=1.64 \mathrm{~g} \mathrm{H}_{2} \mathrm{O} / \mathrm{g} \mathrm{AX}$ ) (Bender et al., 2018b). Subsequently, the sourdough and water was added to the batter and mixed at $300 \mathrm{rpm}$ with a laboratory dough mixer (Bär Varimixer RN10 VL-2, Wodschow \& Co., Denmark) for 1 minute and at $78 \mathrm{rpm}$ for 4 minutes. Always a portion of $400 \mathrm{~g}$ batter were weighed into a baking tin (bottom: L $\times \mathrm{W} \times \mathrm{H}: 15 \times 11 \times 7 \mathrm{~cm}$, top: $15 \times 13 \times 9 \mathrm{~cm})$ and fermented at $30^{\circ} \mathrm{C}$ and $85 \%$ R.H. for 35 minutes. The dough was baked at $180{ }^{\circ} \mathrm{C}$ for 40 minutes (60/rW, MANZ Backtechnik $\mathrm{GmbH}$, Creglingen, Germany). Before the analyses of functional properties, breads were cooled down for $1.5 \mathrm{~h}$ and stored at $20^{\circ} \mathrm{C}$ and $50 \%$ R.H. for 18.5 h. All the baking trials were carried out in duplicates.

\subsection{Determination of the functional properties of batter and bread}

To determine the specific loaf volume, the rapeseed displacement method, following the guidelines of the AACCI (10-05.01) approved method, was used (AACCI, 2000). Duplicate measurements of each loaf were done, resulting in four values for each formulation. The crumb firmness (Fmax) after 25\% deformation was measured according to the AACCI (74-09.01) standard method (AACCI, 2000) with a texture analyser (TA-XT2i, Stable Microsystems ${ }^{\mathrm{TM}}$ Co., Godalming, UK), including a $5 \mathrm{~kg}$ load cell and an SMS $100 \mathrm{~mm}$ diameter compression probe $(\mathrm{p} / 100)$. Relative elasticity (REL) was calculated by dividing Fmax by the 
Table 1. Response surface methodology for the functional properties of GF buckwheat breads with addition of AX and POx Tabelle 1. Response Surface Methode der funktionellen Eigenschaften von GF Buchweizenbroten mit Zugabe von AX und POx

\begin{tabular}{|c|c|c|c|c|c|c|}
\hline $\begin{array}{l}(\mathrm{AX} \\
{[\%]}\end{array}$ & $\begin{array}{c}\text { POx } \\
[\text { nkat/g flour }])^{1}\end{array}$ & $\begin{array}{c}\text { Firmness } \\
{[\mathrm{N}]}\end{array}$ & $\begin{array}{c}\text { Relative elasticity } \\
{[\%]}\end{array}$ & $\begin{array}{l}\text { Specific volume } \\
{\left[\mathrm{cm}^{3} / \mathrm{g} \text { bread }\right]}\end{array}$ & $\begin{array}{c}\text { Pore diameter } \\
{[\mathrm{mm}]}\end{array}$ & $\begin{array}{c}\text { Gas cell area } \\
{[\%]}\end{array}$ \\
\hline 0 & 0 & $9.61 \pm 1.78$ & $64.27 \pm 0.71$ & $1.80 \pm 0.18$ & $2.99 \pm 0.90$ & $38.71 \pm 3.94$ \\
\hline 3 & 0 & $7.20 \pm 1.39$ & $62.39 \pm 0.85$ & $1.93 \pm 0.08$ & $3.07 \pm 0.85$ & $41.02 \pm 1.06$ \\
\hline 6 & 0 & $6.29 \pm 0.76$ & $55.54 \pm 1.21$ & $1.82 \pm 0.06$ & $4.74 \pm 0.20$ & $41.32 \pm 3.59$ \\
\hline 0 & 1 & $4.19 \pm 0.23$ & $66.06 \pm 0.57$ & $1.75 \pm 0.07$ & $3.86 \pm 0.41$ & $41.10 \pm 1.23$ \\
\hline 0 & 2 & $5.92 \pm 1.47$ & $63.73 \pm 1.17$ & $1.84 \pm 0.16$ & $3.76 \pm 0.31$ & $39.60 \pm 2.96$ \\
\hline 32 & 1 & $4.69 \pm 1.49$ & $62.20 \pm 0.96$ & $1.93 \pm 0.09$ & $3.55 \pm 0.46$ & $42.35 \pm 2.22$ \\
\hline 3 & 2 & $6.64 \pm 1.15$ & $59.67 \pm 0.71$ & $1.94 \pm 0.09$ & $2.24 \pm 0.39$ & $37.44 \pm 1.94$ \\
\hline 6 & 1 & $6.80 \pm 0.10$ & $62.60 \pm 0.65$ & $1.97 \pm 0.08$ & $2.04 \pm 0.15$ & $37.44 \pm 1.94$ \\
\hline 6 & 2 & $7.10 \pm 0.43$ & $50.46 \pm 0.04$ & $1.76 \pm 0.00$ & $5.00 \pm 0.66$ & $43.42 \pm 0.48$ \\
\hline Analyses of variance ${ }^{3}$ & & $\mathrm{p}$-Value & $\mathrm{p}$-Value & $\mathrm{p}$-Value & p-Value & p-Value \\
\hline A: Arabinoxylan & & 0.728 & 0.003 & 0.943 & 0.7550 & 0.7920 \\
\hline B: Pyranose- 2 oxidase & & 0.281 & 0.358 & 0.371 & 0.8392 & 0.8708 \\
\hline $\mathrm{AA}$ & & 0.402 & 0.248 & 0.019 & 0.6755 & 0.5771 \\
\hline $\mathrm{AB}$ & & 0.111 & 0.346 & 0.097 & 0.8993 & 0.7918 \\
\hline \multirow[t]{2}{*}{$\mathrm{BB}$} & & 0.056 & 0.176 & 0.349 & 0.6947 & 0.8962 \\
\hline & & $\mathrm{R}^{2}[\%]$ & $\mathrm{R}^{2}[\%]$ & $\mathrm{R}^{2}[\%]$ & $\mathrm{R}^{2}[\%]$ & $\mathrm{R}^{2}[\%]$ \\
\hline & & 73.83 & 87.81 & 76.90 & 11.92 & 11.25 \\
\hline Factors & & $\begin{array}{l}\text { Predicted optimized } \\
\text { factors }\end{array}$ & $\begin{array}{c}\text { Predicted optimized } \\
\text { factors }\end{array}$ & $\begin{array}{c}\text { Predicted optimized } \\
\text { factors }\end{array}$ & $\begin{array}{c}\text { Predicted optimized } \\
\text { factors }\end{array}$ & $\begin{array}{c}\text { Predicted optimized } \\
\text { factors }\end{array}$ \\
\hline $\mathrm{AX}$ & & 1.92 & 0.00 & 2.24 & 6.00 & 3.27 \\
\hline POx & & 1.27 & 1.05 & 2.00 & 2.00 & 0.67 \\
\hline
\end{tabular}

${ }^{I}$ The values indicate the amount of ingredients; Arabinoxylan $(A X)$ is expressed as \% additionally added to the total amount of buckwheat flour

${ }^{2}$ The central point (3\% AX and 1 nkat $P O x / g$ flour) was analysed in triplicates

${ }^{3} A A=$ The quadratic factor of $A X ; B B=$ The quadratic factor of $P O x ; A B=$ The interaction effect of $A X$ and $P O x$

force at the end of the relaxation time (F120). Six rectangular samples of $3 \times 3 \times 2 \mathrm{~cm}(\mathrm{~L} \times \mathrm{W} \times \mathrm{H})$ were cut out of each bread loaf. To determine the crumb colour, a Digi-Eye System (Carl von Gehlen Spezialmaschinen und Zubehör GmbH \& Co. KG, Mönchengladbach, Germany), including a digital camera D-90 Nikon (Tokyo, Japan), was used. Analysis was performed in duplicate measurements.

Crumb porosity of a $20 \times 20 \mathrm{~mm}$ square of the centres of two bread slices was analysed applying the ImageJ software (1.47v, National Institute of Health, Bethesda, USA). The mean pore diameter and total cell area were measured. In total, always four values were obtained for each formulation. The titratable acidity (TTA), measured according to the ICC Standard method No. 145 (ICC, 1995), and the pHvalue were analysed before and after the fermentation of the batter to control its acidity.

\subsection{Statistical analyses}

Statistical analyses were performed using STATGRAPHICS Centurion 18, version 18.1.02 (Statpoint Technolo- gies, Inc., Warrenton, Virginia, USA). To determine significant differences between the samples, a one-way ANOVA (analysis of variance; $\alpha=0.05$ ) and Tukey HSD test were used, while for non-parametric samples, a Kruskal-Wallis test $(\alpha=0.05)$ and Games-Howell test were applied. Significant differences are indicated by different lower case letters in the same column, when $\mathrm{p} \leq 0.05$.

\section{Results and discussion}

\subsection{Effect of sourdough on buckwheat batter and bread properties}

The use of sourdough in bread making is widely established to improve textural, sensory and nutritional bread properties, and it further affects the final $\mathrm{pH}$ of the bread batter. The acidification of the batter in turn can affect structure-forming molecules in the flour and alter dough stability (Arendt et al., 2007). For that purpose, the effect of sourdough addition on the functional properties 
of buckwheat batters and breads was studied. As shown in Figure 1, dough acidity showed a direct proportional relationship to sourdough addition. Although sourdough addition did not significantly change the $\mathrm{pH}$ of the batter, TTA was significantly increased. After fermentation, the $\mathrm{pH}$ of the batter decreased and TTA increased.

The effect of sourdough on the functional properties of buckwheat breads is displayed in Table 2. Higher sourdough concentration lead to lower crumb firmness and relative elasticity and improved crumb porosity (Figures 3 A-D). Specific volume was not significantly influenced. The increased acidification of the batter with $82 \%$ sourdough (Figure 1) most likely affected the structureforming components of the flour (e.g., proteins, starch and AX) (Arendt et al., 2007; Bender et al., 2017a) and resulted in the significantly lowest crumb firmness (Table 2). For wheat bread, low $\mathrm{pH}$ levels were previously related to changes in a gluten and AX network (Arendt et al., 2007) as well as to the modifications in crumb firmness (Schober et al., 2003). In the current study, a non-homogenous pore structure was observed for all breads, except for breads with $82 \%$ acidification of total flour weight, which resulted in a very continuous pore structure, with rather small sized gas cells of high uniformity.

Based on these results, sourdough concentration was set at $82 \%$ for all further trials with AX and POx addition.

\subsection{Effect of AX and POx on buckwheat bread properties}

To evaluate the effect of AX and/or POx on the quality of wholemeal buckwheat sourdough breads, a response surface methodology was used. Goodness-of-fit statistics for firmness, relative elasticity and specific volume were con- sidered as high, as $\mathrm{R}^{2}$ values indicated $73.83,87.81$ and 76.90 , respectively (Table 1 ). On the other hand, the $\mathrm{R}^{2}$ values for crumb pore diameter and gas cell area were extremely low, 11.92 and 11.25 , respectively; thus, the used model was not appropriate for describing the effects of AX and $\mathrm{POx}$ on crumb porosity.

The quadratic factor of AX (AA) positively influenced the loaf volume ( $p=0.019)$, whereas AX (A) had a negative effect on the relative elasticity $(p=0.003)$. On the contrary, neither AX nor POx or their interaction significantly affected crumb firmness $(p>0.05)$. The response surface plot for firmness (Figure $2 \mathrm{~A}$ ) indicated that the lowest values were achieved with 2-3\% AX and 1 nkat $\mathrm{POx} / \mathrm{g}$ flour, while higher levels of AX and/or POx increased firmness, although these effects were not significant. Ayala-Soto et al. (2017) recommended a higher addition of AX (6\%) without enzyme substitution to GF bread formulations to optimize firmness. As already mentioned, crumb elasticity was reduced by the addition of AX, but still all breads showed a high relative elasticity, ranging between 62.20 and $66.06 \%$, except for the formulations 6AX0POx and 6AX2POx (Table 1). Thus, in contrast to literature on GF breads, the elasticity of buckwheat breads in the current work was considered as acceptable and all formulations (except for 6AX0POx and 6AX2POx) showed an even higher elasticity than that of wheat breads without additives (56.6 $\pm 1.11 \%$ ) (Schoenlechner et al., 2013). In a previous study of Bender et al. (2017a), they presented lower relative elasticity $(55.68 \pm 0.37 \%)$ of control breads, using the same buckwheat flour. However, mixing speed and proofing time were slightly different in the current research. According to Gómez et al. (2013), the process steps (e.g., mixing and fermentation) are crucial for final bread quality and could thus explain the differences in texture. In their study, it was

Table 1. Response surface methodology for the functional properties of GF buckwheat breads with addition of AX and POx

Tabelle 1. Response Surface Methode der funktionellen Eigenschaften von GF Buchweizenbroten mit Zugabe von AX und POx

\begin{tabular}{cccc}
\hline SD & Firmness \\
{$[\%]^{2}$} & {$[\mathrm{~N}]^{1}$} & $\begin{array}{c}\text { Relative elasticity } \\
{[\%]^{1,3}}\end{array}$ & $\begin{array}{c}\text { Specific volume } \\
{[\mathrm{cm} 3 / \mathrm{g} \mathrm{bread}]^{1,3}}\end{array}$ \\
\hline 18 & $14.08 \pm 1.38 \mathrm{c}$ & $68.08 \pm 0.12 \mathrm{~b}$ & $1.82 \pm 0.05$ \\
36 & $12.46 \pm 0.63 \mathrm{bc}$ & $67.81 \pm 0.61 \mathrm{~b}$ & $1.77 \pm 0.02$ \\
54 & $10.82 \pm 2.14 \mathrm{~b}$ & $65.65 \pm 0.78 \mathrm{a}$ & $1.80 \pm 0.10$ \\
82 & $9.61 \pm 1.78 \mathrm{a}$ & $64.27 \pm 0.71 \mathrm{ab}$ & $1.80 \pm 0.18$ \\
$p$-Value & 0.000 & 0.007 & 0.768 \\
\hline
\end{tabular}

${ }^{1}$ Mean value \pm standard deviation. Different lower case letters in the same column indicate significant differences ( $\left.p \leq 0.05\right)$

${ }^{2} \%$ of total flour weight;

${ }^{3}$ Non-parametric data. The statistical analysis of these data was done with the Kruskal-Wallis ANOVA and the Games-Howell test 


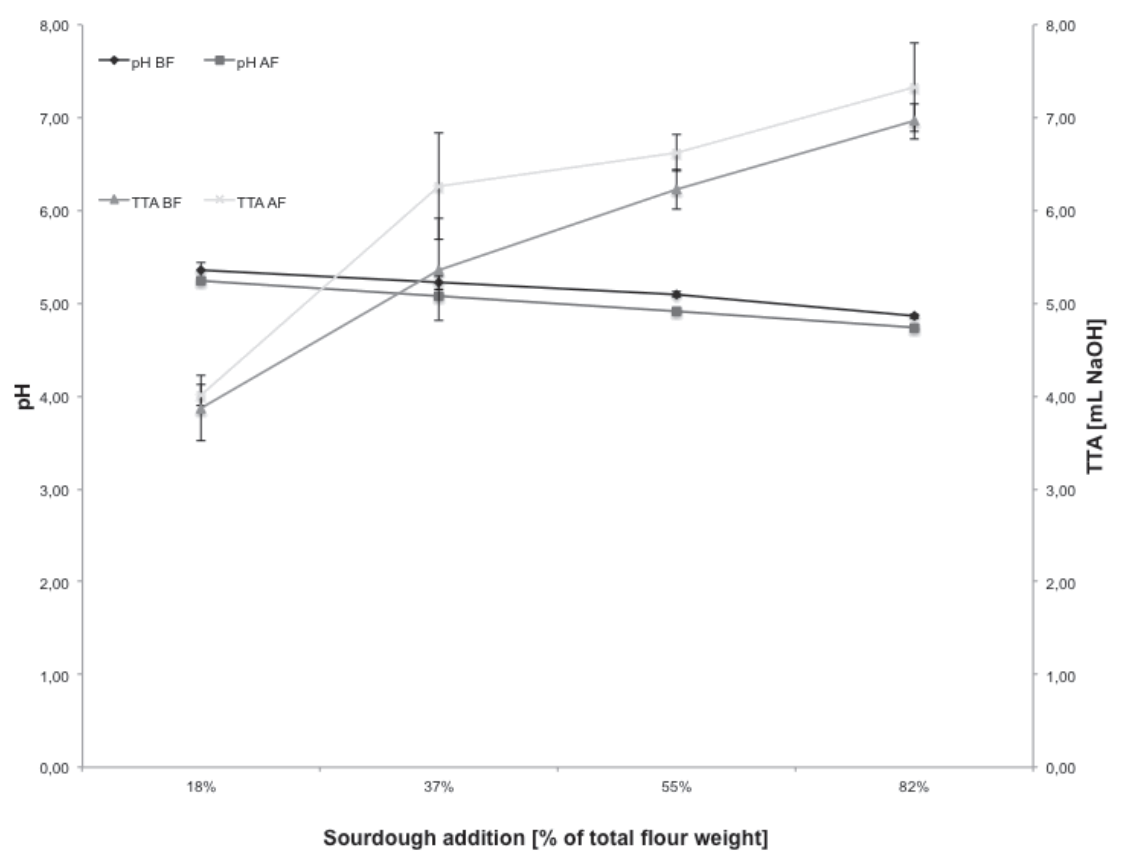

Figure 1. Influence of sourdough on batter acidification, measured by $\mathrm{pH}$ and titratable acidity (TTA) before (BF) and after fermentation (AF) Abbildung 1. Einfluss von Sauerteig auf die Säuerung des Teiges, gemessen anhand des $\mathrm{pH}$ und der titrierbaren Säure (TTA) vor (BF) und nach der Fermentierung (AF)

concluded that mixing at a lower speed and for a longer mixing period resulted in higher specific loaf volume and a decrease in firmness. In the current study, specific volume had a significant maximum at $3 \% \mathrm{AX}$ addition (Table 1 : the quadratic effect for $\mathrm{AX}$ was significant), which was further increased with the addition of $\mathrm{POx}$, although the latter not significantly (Figure $2 \mathrm{C}$ ). AX and POx did not always act synergistically, as some of the combinations (e.g., 6AX2POx) showed detrimental effects on the relative elasticity and specific volume. These effects could be attributed to the formation of hydroxyl radicals from $\mathrm{H}_{2} \mathrm{O}_{2}$, which further degrade the AX structure by radical cleavage, as described by Schooneveld-Bergmans et al. (1999). Another explanation would be the cross-linking of water-soluble AXs into water-insoluble AXs (Bender et al., 2018a; Decamps et al., 2013), which could negatively affect the functional bread properties (Izydorczyk and Biliaderis, 2007). Water-insoluble AXs could probably form a barrier for AX and protein network formation in GF batter systems.

Considering the pore structure of the bread crumb, the pore diameter as well as the gas cell area were increased by the addition of AX (e.g., formula 6AX0POx). But as the porosity of buckwheat sourdough breads already showed an acceptable porosity $(=\mathrm{a}$ homogenous pore size and high cell area) without AX or POx (Figure 3 D), differences after AX and $\mathrm{POx}$ addition were only minor and thus not significant.

In addition to the texture parameters, the crumb colour was analysed. All formulas with addition of AX showed a significant increase in redness $\left(\mathrm{a}^{*}\right)$ and yellowness $\left(\mathrm{b}^{*}\right)$ compared to the control breads (Control: $\mathrm{a}^{*}=8.32 \pm 0.24 ; \mathrm{b}^{*}=16.55$ $\pm 0.45 ; 3$ AX0POx: $a^{*}=10.22 \pm 0.18 ; b^{*}=20.71 \pm 0.75$; 6AX0POx: $\left.a^{*}=11.14 \pm 0.23 ; b^{*}=21.78 \pm 0.32\right)$. Lightness $\left(\mathrm{L}^{*}\right)$ of the crumb was only significantly decreased with the addition of 6\% AX (6AX0POx, 6AX1POx and 6AX2POx) compared to the control breads $\left(\mathrm{L}^{*}=55.42 \pm 0.39\right)$, resulting in $L^{*}$-values of $46.75 \pm 1.57,47.84 \pm 0.73$ and 46.10 \pm 0.08 , respectively. This colour change is mainly attributed to the dark colour of the added AX, and to a small extent, it might also have been caused by the increased caramelization due to its higher sugar content. On the other hand, the addition of POx did not affect the crumb colour (data not shown). Crumb colour of all formulas with AX and POx is visually presented in Figure 3.

The $\mathrm{pH}$ of the buckwheat batters was unaffected by the addition of AX and POx and remained between 4.77 and 4.92 and between 4.69 and 4.82, before and after fermentation, respectively. These $\mathrm{pH}$ values are favourable for $\mathrm{AX}$ cross-linking, as according to Izydorczyk et al. (1990) it 
Table 3. Comparison of functional properties of buckwheat bread with wholemeal and refined flour

Tabelle 3. Vergleich der funktionellen Eigenschaften von Buchweizenbrot mit Vollkorn- und Auszugsmehl

\begin{tabular}{|c|c|c|c|c|c|c|c|c|c|c|}
\hline \multirow[t]{2}{*}{ Flours } & \multirow{2}{*}{$\begin{array}{c}\mathrm{AX} \\
{[\%]^{2}}\end{array}$} & \multirow{2}{*}{$\begin{array}{c}\text { POx } \\
\text { [nkat/g } \\
\text { flour] }\end{array}$} & \multirow{2}{*}{$\begin{array}{c}\text { Firmness } \\
{[\mathrm{N}] 1,4}\end{array}$} & \multirow{2}{*}{$\begin{array}{c}\text { REL } \\
{[\%]^{1,3,4}}\end{array}$} & \multirow{2}{*}{$\begin{array}{l}\text { Specific volume } \\
{\left[\mathrm{cm}^{3} / \mathrm{g} \text { bread }\right]^{1,4}}\end{array}$} & \multicolumn{3}{|c|}{ Colour of crumb ${ }^{4}$} & \multirow{2}{*}{$\begin{array}{l}\text { Pore diameter } \\
{[\mathrm{mm}]^{1,4}}\end{array}$} & \multirow{2}{*}{$\begin{array}{c}\text { Gas cell area } \\
{[\%]^{1}}\end{array}$} \\
\hline & & & & & & $\mathrm{L}^{*}$ & $a^{*}$ & $b^{*}$ & & \\
\hline Wholemeal & 0 & 0 & $9.61 \pm 1.78^{b}$ & $64.27 \pm 0.71 \mathrm{c}$ & $1.80 \pm 0.18$ & $55.42 \pm 0.39 c$ & $8.32 \pm 0.24^{a}$ & $16.55 \pm 0.45^{a}$ & $2.99 \pm 0.90$ & $38.71 \pm 3.94^{\mathrm{a}}$ \\
\hline Wholemeal & 3 & 1 & $4.69 \pm 1.49^{\mathrm{a}}$ & $62.20 \pm 0.96^{\mathrm{b}}$ & $1.93 \pm 0.09$ & $52.43 \pm 1.00^{\mathrm{b}}$ & $9.56 \pm 0.43^{b}$ & $19.63 \pm 1.53^{\mathrm{b}}$ & $3.55 \pm 0.46$ & $42.35 \pm 2.22^{b}$ \\
\hline Refined & 0 & 0 & $10.53 \pm 0.94^{\mathrm{b}}$ & $63.56 \pm 1.33^{b} c$ & $1.88 \pm 0.01$ & $64.35 \pm 1.14 \mathrm{~d}$ & $7.27 \pm 0.58^{\mathrm{a}}$ & $16.18 \pm 0.94^{a}$ & $3.62 \pm 0.60$ & $39.69 \pm 1.15^{a}$ \\
\hline Refined & 3 & 1 & $11.01 \pm 0.94^{\mathrm{b}}$ & $55.28 \pm 3.91^{\mathrm{a}}$ & $1.91 \pm 0.05$ & $51.13 \pm 0.44^{\mathrm{a}}$ & $9.64 \pm 0.25^{\mathrm{b}}$ & $21.33 \pm 0.50^{\mathrm{b}}$ & $2.97 \pm 0.22$ & $40.53 \pm 1.09^{\mathrm{at}}$ \\
\hline $\mathrm{p}$-Value & & & 0.001 & 0.000 & 0.102 & 0.000 & 0.000 & 0.000 & 0.175 & 0.004 \\
\hline
\end{tabular}

${ }^{I}$ Mean value \pm standard deviation. Different lower case letters in the same column indicate significant differences ( $\left.p \leq 0.05\right)$.

${ }^{2}$ Arabinoxylan $(A X)$ is expressed as \% additionally added to the total amount of buckwheat flour

${ }^{3} R E L$, relative elasticity

${ }^{4}$ Non-parametric data. The statistical analysis of these data was done with the Kruskal-Wallis ANOVA and the Games-Howell test.

can occur very fast within an acidic batter; also, oxidation of its ferulic acid has an optimum at $\mathrm{pH} \approx 4$.0. (Bernards et al., 1999). Hence, it is argued that the acidification of the buckwheat batter contributed to the AX gelation.

Overall, the formulation with $3 \% \mathrm{AX}$ and 1 nkat $\mathrm{POx} / \mathrm{g}$ flour was considered to improve the functional properties of wholemeal buckwheat bread the most. The predicted factors of the experimental design suggested a combined use of AX and POx of $1.92 \%$ and 1.27 nkat POx/g flour to lower the firmness and $2.24 \%$ and 2 nkat POx/g flour to enhance the specific volume (Table 1). When both these answers are considered, the best optimum addition seemed to be an addition of $3 \% \mathrm{AX}$ and 1 nkat POx/g flour. A moderate concentration of $\mathrm{POx}$ is able to enhance AX cross-linking by the formation of $\mathrm{H}_{2} \mathrm{O}_{2}$, as seen in the previous research of buckwheat (Bender et al., 2018a) and wheat dough systems (Decamps et al., 2013). A study of Gujral and Rosell (2004) also reported the highest loaf volume and the softest crumb with the combined use of a hydrocolloid (hydroxypropyl methylcellulose) and an oxidative enzyme (GOx) on GF (rice flour) bread.

\subsection{Effect of different buckwheat flours on buckwheat bread properties}

Since most commercially available GF breads are made from refined flours, the effect of addition of AX and POx on the functional properties of bread made from refined buckwheat flour was tested and compared to the breads made from wholemeal buckwheat flour. An addition of 3\% AX and 1 nkat POx/g flour was selected in the bread formulation to determine these effects.
A

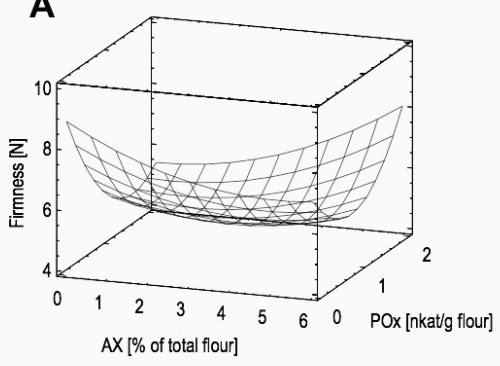

B

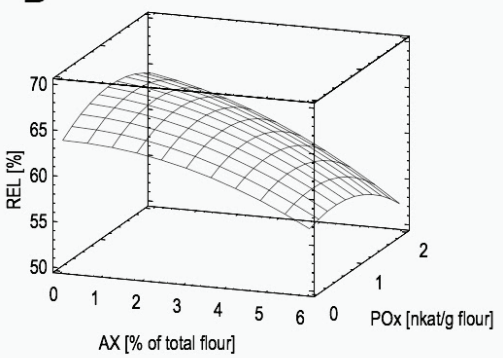

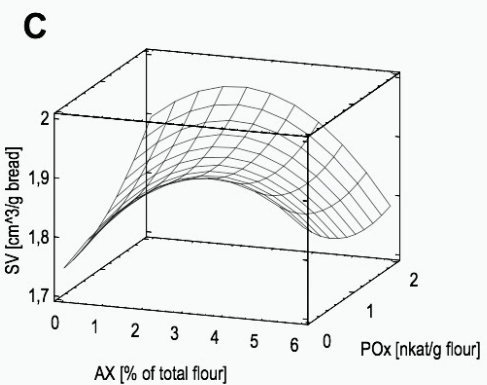

Figure 2. Response surface plots of wholemeal buckwheat breads added with AX and POx of A: firmness; B: relative elasticity (REL) and C: specific volume (SV).

Abbildung 2. „Response surface plots“ der Vollkorn-Buchweizenbrote mit Zugabe von AX und POx A: Krumenfestigkeit; B: relative Elastizität (REL) und C: spezifisches Volumen (SV) 

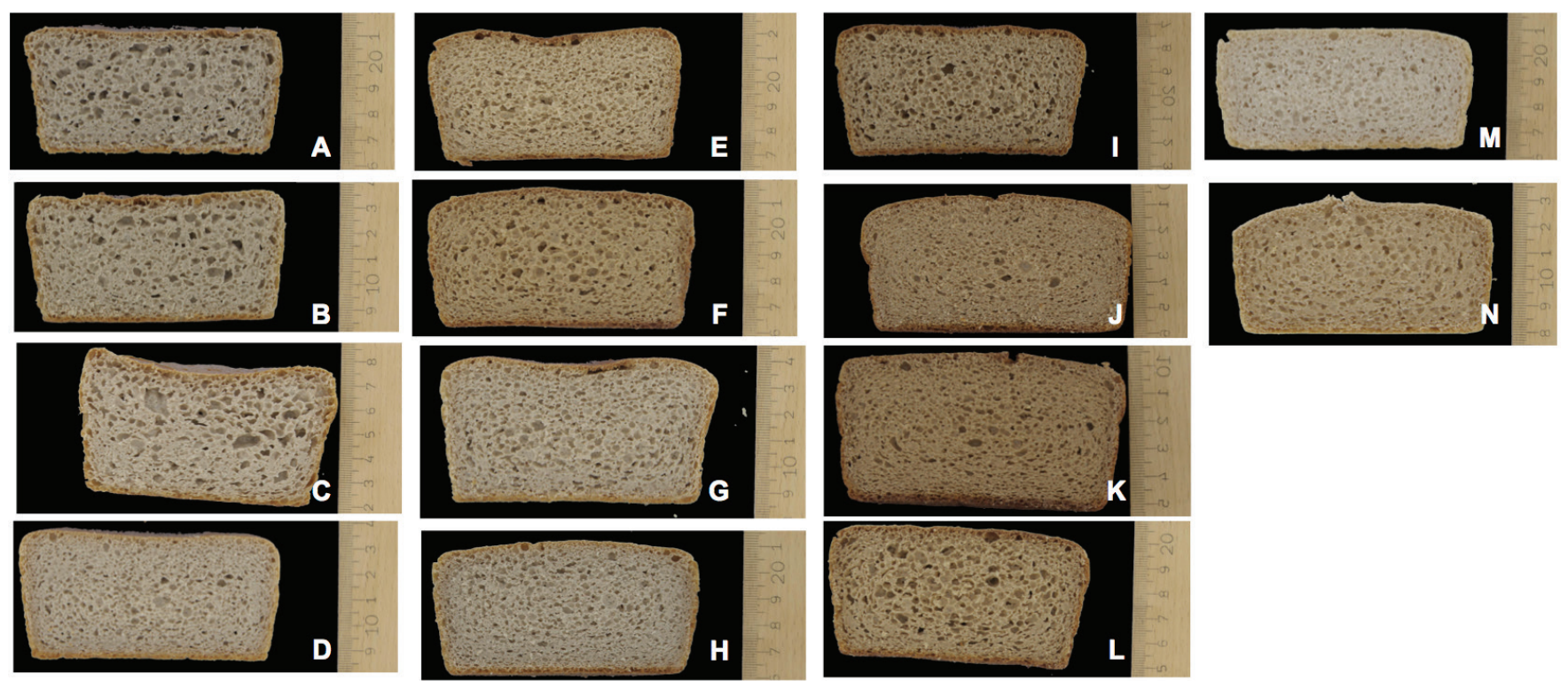

Figure 3. Bread slices of buckwheat breads added with A: $18 \%$ sourdough; B: $36 \%$ sourdough; C: $54 \%$ sourdough; D: $82 \%$ sourdough and control for optimization; E: 3\% AX; F: 6\% AX; G: 1 nkat POx/g flour; H: 2 nkat POx/g flour; I: 3\% AX and 1 nkat POx/g flour; J: 3\% AX and 2 nkat POx/g flour; K: 6\% AX and 1 nkat POx/g flour; L: 6\% AX and 2 nkat POx/g flour; M: control with refined flour; N: 3\% AX and 1 nkat POx with refined flour

Abbildung 3. Visuelle Darstellung der Krume von allen gebackenen Buchweizenrezepturen mit A: 18\% Sauerteig; B: 36\% Sauerteig; C: 54\% Sauerteig; D: 82\% Sauerteig und Kontrolle für Optimierung; E: 3\% AX; F: 6\% AX; G: 1 nkat POx/g Mehl; H: 2 nkat POx/g Mehl; I: 3\% AX und 1 nkat POx/g Mehl; J: 3\% AX und 2 nkat POx/g Mehl; K: 6\% AX und 1 nkat POx/g Mehl; L: 6\% AX und 2 nkat POx/g Mehl; M: Kontrolle mit Auszugsmehl; N: 3\% AX und 1 nkat POx/g Mehl mit Auszugsmehl

As Table 3 shows, the specific volume and relative elasticity were not different between the breads produced from refined or wholemeal flour without any AX or POx addition, and the crumb firmness was higher in bread from refined flour than from wholemeal flour. This is in contradiction to the previous investigations (for wheat bread) that associated wholemeal flours with a low specific volume, arguing that the high amount of bran particles could damage or destroy gas cells by piercing them (Hager et al., 2012). On the other hand, Phimolsiripol et al. (2012) also found that rice bran addition to rice-based GF bread did significantly improve the final bread quality (volume and texture). In their study, it was also argued that the addition of bran is able to deliver a certain stability to GF doughs, as they often contain very high amounts of starch giving a dense structure.

After AX and POx addition, again bread volume remained the same between the two types of flours, but relative elasticity of buckwheat breads significantly differed between the two flours tested; in refined flour, it became lower. While AX and POx significantly decreased the firmness in wholemeal buckwheat bread, they had no effect in the refined flour breads. For refined and wholemeal buckwheat breads, it was visually as well as statistically perceived that the addition of
3\% AX and 1 nkat POx resulted in a darker crumb colour compared to its control (Table 3 and Figures 3 D, I, M and $\mathrm{N})$. The darkening in colour is desirable, as GF breads are often very pale compared to their gluten-containing counterparts due to the dominant use of plain starches instead of flour (Gallagher et al., 2003).

The different refinements of buckwheat flour did not affect the pore structure (Table 3). Wholemeal and refined buckwheat bread showed a similar pore size with a high uniformity (Figure 3).

From the present findings, differences among the buckwheat flours are mainly attributed to their variation in chemical composition, since the protein and dietary fibre content of wholemeal buckwheat is higher than that of the refined buckwheat flour, as described in chapter 2.1. This is in agreement with Martínez et al. (2013), who suggested that dietary fibres have various benefits on GF bread properties and with Sciarini et al. (2010), who reported improved GF bread- and dough quality with the use of GF flours high in protein. Further, it is assumed that the improved texture of breads with wholemeal flour could be related to an enhanced cross-linking of AX and flour proteins. Besides, the particle size of the two flours var- 
ied slightly, as the refined flour showed a finer particle size (= standard particle size of $250 \mu \mathrm{m}$ ), while in the wholemeal flour, coarse bran particles remained after milling. The coarser bran particles of the wholemeal flour might also positively affect the crumb structure and its hardness. A study of De la Hera et al. (2014) focused on the particle size of different maize flours and associated a higher bread quality, especially a higher loaf volume and a softer bread crumb, with coarser flours. The acceptable texture of breads with wholemeal flour is highly targeted because of the techno-functional and health benefits related to dietary fibres. On the other hand, the differences between wholemeal and refined buckwheat breads could be associated with the different water holding capacities of the flours. In the current work, the same amount of water was added to both buckwheat formulations to simplify their comparison. The water holding capacity of the refined buckwheat flour was not determined and this could have significantly affected the quality of the refined breads. Hence, changes in water addition or proofing time of refined buckwheat breads might improve its quality.

\section{Conclusion}

From the current research, buckwheat breads added with sourdough and a moderate amount of AX (up to 3\%) and POx (up to $1 \mathrm{nkat} / \mathrm{g}$ flour) showed a highly acceptable specific volume, crumb firmness, a good pore structure and an appealing crumb colour, suggesting a positive effect on those factors. However, AX and POx, added in too high amounts negatively affected the bread quality. Their ideal concentration therefore needs to be examined and considered carefully. Breads from wholemeal buckwheat flour revealed a significantly enhanced crumb texture compared to those from the refined flour. Hence, GF sourdough bread formulations including wholemeal buckwheat flour, AX addition up to $3 \%$ and $\mathrm{POx}$ are not only interesting for food manufacturers, but could be also a good step towards the availability of natural and healthy foods for gluten intolerant people.

\section{Acknowledgements}

This work was financially supported by the Austrian Scientific Research Fund (FWF) (project I1842-312 N28) and the Hungarian Scientific Research Fund (OTKA) (ANN-
114554). The authors would like to thank Edina Jaksics (Budapest, Hungary) and Markus Regner (Vienna, Austria) for their kind collaboration.

\section{References}

AACCI (2000): Approved methods of the American Association of Cereal Chemists. American Association of Cereal Chemists, $10^{\text {th }}$ ed., St. Paul, Minnesota, USA.

Arendt, E.K., Ryan, L.A.M. and F. Dal Bello (2007): Impact of sourdough on the texture of bread. Food Microbiology 24, 165-174.

Ayala-Soto, F.E., Serna-Saldívar, S.O. and J. Welti-Chanes (2017): Effect of arabinoxylans and laccase on batter rheology and quality of yeast-leavened gluten-free breads. Journal of Cereal Science 73, 10-17.

Bender, D., Fraberger, V., Szepasvári, P., D’Amico, S., Tömösközi, S., Cavazzi, G., Jäger, H., Domig, K.J. and R. Schoenlechner (2017a): Effects of selected lactobacilli on the functional properties and stability of glutenfree sourdough bread. European Food Research and Technology 244, 1037-1046.

Bender, D., Nemeth, R., Wimmer, M., Götschhofer, S., Biolchi, M., Török, K., Tömösközi, S., D’Amico, S. and R. Schoenlechner (2017b): Optimization of arabinoxylan isolation from rye bran by adapting extraction solvent and use of enzymes. Journal of Food Science 82, 2562-2568.

Bender, D., Nemeth, R., Cavazzi, G., Turoczi, F., Schall, E., D’Amico, S., Török, K., Lucisano, M., Tömösközi, S. and R. Schoenlechner (2018a): Characterization of rheological properties of rye arabinoxylans in buckwheat model systems. Food Hydrocolloids 80, 33-41.

Bender, D., Regner, M., D’Amico, S., Jäger, H., Tömösközi, S. and R. Schoenlechner (2018b): Effect of differently extracted arabinoxylan on gluten-free sourdough-bread properties. Journal of Food Quality 2018, 5719681.

Bernards, M.A., Fleming, W.D., Llewellyn, D.B., Priefer, R., Yang, X., Sabatino, A. and P.L. Plourde (1999): Biochemical characterization of the suberization-associated anionic peroxidase of potato. Plant Physiology 121, $135-146$.

Buksa, K. (2016): Application of model bread baking in the examination of arabinoxylan - Protein complexes in rye bread. Carbohydrate Polymers 148, 281-289.

De la Hera, E., Rosell, C.M. and M. Gomez (2014): Effect of water content and flour particle size on gluten-free 
bread quality and digestibility. Food Chemistry 151, 526-531.

Decamps, K., Joye, I.J., Rakotozafy, L., Nicolas, J., Courtin, C.M. and J.A. Delcour (2013): The bread dough stability improving effect of pyranose oxidase from Trametes multicolor and glucose oxidase from Aspergillus niger: Unraveling the molecular mechanism. Journal of Agricultural and Food Chemistry 61, 7848-7854.

Figueroa-Espinoza, M.-C., Poulsen, C., Borch Søe, J., Zargahi, M.R. and X. Rouau (2002): Enzymatic solubilization of arabinoxylans from isolated rye pentosans and rye flour by different endo-xylanases and other hydrolyzing enzymes. Effect of a fungal laccase on the flour extracts oxidative gelation. Journal of Agricultural and Food Chemistry 50, 6473-6484.

Gómez, M., Talegón, M. and E. Hera (2013): Influence of mixing on quality of fluten-free bread. Journal of Food Quality 36, 139-145.

Grootaert, C., Delcour, J.A., Courtin, C.M., Broekaert, W.F., Verstraete, W. and T. Van de Wiele (2007): Microbial metabolism and prebiotic potency of arabinoxylan oligosaccharides in the human intestine. Trends in Food Science \& Technology 18, 64-71.

Gujral, H.S. and C.M. Rosell (2004): Improvement of the breadmaking quality of rice flour by glucose oxidase. Food Research International 37, 75-81.

Hager, A.-S., Wolter, A., Czerny, M., Bez, J., Zannini, E., Arendt, E.K. and M. Czerny (2012): Investigation of product quality, sensory profile and ultrastructure of breads made from a range of commercial gluten-free flours compared to their wheat counterparts. European Food Research and Technology 235, 333-344.

ICC (1995): ICC Standard Method No. 145. Determination of Acidity (acc. to Schulerud) for Cereals and Cereal Products. International Association for Cereal Science and Technology, Vienna, Austria.

Izydorczyk, M. and C. Biliaderis (2007): Arabinoxylans: Technologically and nutritionally functional plant polysaccharides. In: Biliaderis, C.G. and M.S. Izydorczyk (Eds.): Functional food carbohydrates. CRC Press, Boca Raton, FL, USA, pp. 249-290.

Izydorczyk, M.S., Biliaderis, C.G. and W. Bushuk (1990): Oxidative gelation studies of water-soluble pentosans from wheat. Journal of Cereal Science 11, 153-169.
Martínez, M.M., Marcos, P. and M. Gómez (2013): Texture Development in Gluten-Free Breads: Effect of Different Enzymes and Extruded Flour. Journal of Texture Studies 44, 480-489.

Mir, S.A., Shah, M.A., Naik, H.R. and I.A. Zargar (2016): Influence of hydrocolloids on dough handling and technological properties of gluten-free breads. Trends in Food Science \& Technology 51, 49-57.

Moroni, A.V., Dal Bello, F. and E.K. Arendt (2009): Sourdough in gluten-free bread-making: An ancient technology to solve a novel issue? Food Microbiology 26, 676-684.

Moroni, A.V., Arendt, E.K. and F. Dal Bello (2011): Biodiversity of lactic acid bacteria and yeasts in spontaneously-fermented buckwheat and teff sourdoughs. Food Microbiology 28, 497-502.

Naqash, F., Gani, A., Gani, A. and F.A. Masoodi (2017): Gluten-free baking: Combating the challenges - A review. Trends in Food Science \& Technology 66, 98-107.

Phimolsiripol, Y., Mukprasirt, A. and R. Schoenlechner (2012): Quality improvement of rice-based gluten-free bread using different dietary fibre fractions of rice bran. Journal of Cereal Science 56, 389-395.

Renzetti, S. and C.M. Rosell (2016): Role of enzymes in improving the functionality of proteins in non-wheat dough systems. Journal of Cereal Science 67, 35-45.

Rosell, C.M., Santos, E. and C. Collar (2010): Physical characterization of fiber-enriched bread doughs by dual mixing and temperature constraint using the Mixolab ${ }^{\odot}$. European Food Research and Technology 231, 535544.

Rosell, C.M., Bajerska, J. and A.F. El Sheikha (2015): Bread and Its Fortification: Nutrition and Health Benefits. CRC Press, Boca Raton, FL, USA.

Schober, T.J., Dockery, P. and E.K. Arendt (2003): Model studies for wheat sourdough systems using gluten, lactate buffer and sodium chloride. European Food Research and Technology 217, 235-343.

Schoenlechner, R., Szatmari, M., Bagdi, A. and S. Tömösközi (2013): Optimisation of bread quality produced from wheat and proso millet (Panicum miliaceum L.) by adding emulsifiers, transglutaminase and xylanase. LWT - Food Science and Technology 51, 361366. 
Schooneveld-Bergmans, M.E.F., Dignum, M.J.W., Grabber, J.H., Beldman, G. and A.G.J. Voragen (1999): Studies on the oxidative cross-linking of feruloylated arabinoxylans from wheat flour and wheat bran. Carbohydrate polymers 38, 309-317.

Sciarini, L.S., Ribotta, P.D., León, A.E. and G.T. Pérez (2010): Influence of gluten-free flours and their mixtures on batter properties and bread quality. Food and Bioprocess Technology 3, 577-585.
Spadiut, O., Posch, G., Ludwig, R., Haltrich, D. and C.K. Peterbauer (2010): Evaluation of different expression systems for the heterologous expression of pyranose 2-oxidase from Trametes multicolor in E. coli. Microbial Cell Factories 9, 14. 